\title{
SOBRE LA DIFICULTAD DE SER CAROLINA CORONADO: CONTEMPLACIÓN Y PRAXIS FENOMENOLÓGICA
}

\author{
Rebecca HAIDT
}

Ohio State University

\section{RESUMEN}

Este ensayo ofrece una aproximacion a un grupo de poemas tempranos escritos por Coronado en los años 40. Motivado por la aparente dificultad de trascender un marco analitico de polarizaciones entre, por ejemplo, represion y libertad, masculino y femenino, etc., el ensayo enfoca la «contemplacion» empleada por la poeta para profundizar cuestiones de la naturaleza del conocimiento mismo. El analisis de las funciones de tres nucleos semánticos - «amor,» «cantar»y «espíritus»- por medio de los cuales la voz poética de Coronado se concentra en el fenómeno (para decirlo así) de la propia presencia, revela evidencia de una «praxis fenomenológica» llevada a cabo por Coronado: esto es, la indagación, llevada a cabo por el yo poético de Coronado, acerca de la complejidad de la experiencia vivida; y a la voz del sujeto discursivo que reflexiona sobre las implicaciones del fenómeno de ser dentro, y a través, de marcos temporales. Estos tres nucleos semanticos le permiten al poeta indagar en la propia existencia humana vivida como sintesis en desarrollo (Alcoff). Un ejercicio en el cual el sujeto poético, enmarañado en lo que Merleau-Ponty elaborara como «el mundo de la carne», se empodera para articular la complejidad inherente en cualquier historia personal del «cuerpo fenomenal».

Palabras clave: Carolina Coronado, poesía romántica.

\section{ABSTRACT}

This essay offers an approach to a group of poems written by Coronado in the 1840s. Motivated by the apparent difficulty of transcending a critical framework marked by polarizations such as masculine vs. feminine, repression vs. freedom, etc., the present discussion focuses on the «contemplation» employed by the poet to explore questions 
concerning the nature of knowledge itself. Analyzing the functions of three interrelated semantic nuclei - «amor,» «espiritus» and «cantar» - this essay argues for evidence of a phenomenological practice elaborated by Coronado: that is, of the poetic self's inquiry into the complexity of lived experience; and the discursive subject's reflection on the implications of phenomenal being in and across temporal frameworks. A critical approach informed by phenomenology reveals that these three semantic nuclei permit the poet to interrogate (her) human existence as a developing synthesis (Alcoff), and enable the poetic subject to explore the difficulties and complexities of the the phenomenal body enmeshed in the world of flesh (Merleau-Ponty).

Key words: Carolina Coronado, romantic poetry.

Una mujer sentada en una silla, cosiendo mientras rodeada por la propia familia, ¿habrá figura más representativa del «ángel del hogar» de mediados del siglo XIX? Y una mujer que se escapa de los quehaceres domésticos para entregarse a componer poemas originales sobre, o la libertad, o las flores, o el amor, ésta será la mismísima imagen de una poetisa romántica, ¿no es cierto? Artista que anhela la libertad, frente a ángel de la domesticidad: la polarización de estas dos figuras ha nutrido la crítica de la obra poética de Carolina Coronado, no obstante el hecho de que Coronado misma hubiera sido, no dos tipos de mujer incompatibles, sino (al fin y al cabo) un ser de carne y hueso. Una persona viva cuya respiración ligeramente hiciera vibrar el aire de la habitación donde manos y cuerpo estuvieran ocupados con aguja e hilo. Y al ponerme a imaginar de esta manera a Carolina Coronado, he de reconocer mi propio predicamento de asombro y confusión, ya que eso de comprender a un ser humano es (desde luego) un asunto muy complicado. Por lo tanto, elijo enfocar aquí sólo ciertos aspectos específicos del discurso poético creado por Coronado. Quisiera evitar que mi análisis le atribuya una topografía divisible en territorios distintos de cuerpo y cerebro, subjetividad y objetividad, represión y libertad. Me pregunto: ¿será practicable una aproximación que permita a la vez analizar la voz poética y recuperar algo de la complejidad situacional de la persona viva que compuso los poemas bajo discusión? A la hora de aproximarme al yo poético de Coronado, ¿será posible construir un puente entre, por un lado, un marco crítico que proponga el predominio de claras polarizaciones como (por ejemplo) libertad-represión, y, por otro, un marco analítico que reconozca (o quizás mejor dicho, evite el desplazamiento de) la complejidad vivida de una persona -y cabe señalar aquí la resonancia etimológica de esta palabra, enraizada en la voz (per sona) de un sujeto- cuya presencia sea trazable discursivamente? 
Es verdad que Coronado compuso muchos de sus primeros poemas mentalmente mientras cosía, bordaba, o llevaba a cabo otras tareas dentro del hogar, a falta de fácil acceso a pluma y papel. Es también verdad que rabiaba por la oportunidad de estarse a solas para pensar en preguntas (referentes a los misterios del tiempo, del universo, etc.) que su obra poética compartiría con otros escritores del Romanticismo europeo, por ejemplo Wordsworth (no obstante diferencias de edad, lugar de nacimiento, etc.). Coronado-cosiendo, meditando- era agudamente consciente de lo complejo de la situación que vivía: «Esto es difícil,» escribió a Hartzenbusch desde Badajoz: «estoy como un pájaro sin alas; mucha ansia de volar y precisada a permanecer fija» (431). Esto es difícil - no sorprende que la poeta indagara constantemente en las relaciones no fácilmente discernibles entre lo que se vivía en el momento y los marcos temporales llamativos de imaginación y memoria. Para describir esta conciencia de la doblez - de la dificultad- de la propia experiencia, Coronado eligió la palabra «contemplación» (carta a Hartzenbusch, 1999: 424). De este modo, Coronado refería al complejo experiencial de su propio espacio de composición: siendo el «espacio de composición» ese espacio de conocimiento situado en el presente vivido dentro del cual el sujeto poético discursivamente deja explayar su voz y articular preguntas ${ }^{1}$.El estado de contemplación le permitía crear un espacio de composición que a la vez comprendía, e iba más allá de, aquello en que ojos y oído estaban forzados a enfocarse dentro del campo inmediato de actividad en el presente.

La contemplación le permitió a la poeta dar voz a un sujeto poético contemplador del fenómeno del propio ser. Imagino que a Coronado no le habría sido fácil encontrar palabras que le sirvieran para captar discursivamente las muchas ideas, memorias, sensaciones y capacidades que informaran el espacio de composición en el cual trabajaba. Absorta por tal búsqueda, la poeta lucía abstraída de un modo que provocaba la crítica de los demás: «esta contemplación perjudicaba al buen desempeño de mis labores,» comentó Coronado a Hartzenbusch, "y me daba un aire distraído que hacía reír a los extranjeros y molestaba a mis parientes» (Cartas...,1999: 424).

La risa despectiva de los «extranjeros» parece invitarnos a cuadrarla dentro de la represión de género típica de la sociedad española de la primera mitad del siglo XIX, e incluso a comprenderla como síntoma del rígido marco social dentro del cual la gente de un pueblo de provincias condenara toda novedad (tal como sería, supuestamente, el espectáculo de una joven que

1. Me sirvo aquíde un concepto—espacio de composición—desarrollado por Clark (1997).

Anales, 23, 2011, pp. 233-257 
no prestara suficiente atención a «sus labores»)2. Podemos asociar esa risa con las expectativas de una sociedad que conceptualiza (como Valis bien ha observado) al ser femenino dentro del binario bueno-malo, virtud-pecado: o mujer aceptada o poetisa rechazada; "o escritora o madre-esposa. O todo o nada» (1991: 29). De igual atractivo sería una caracterización de la risa despectiva como sinécdoque de un "predicamento romántico»: después de todo, no digamos que Coronado, al hacerse poeta muy pública hacia finales de la década de los 40, no hubiera aceptado el reto de ejercer su voz poética frente a la esperada sumisión a la tradición; ni que, al entregarse a efusiones e inquietudes personales (por medio de la «contemplación»), no hubiera elegido -en alianza con otros muchos hombres y mujeres de su generación- vivir su propia rebelión en contra de la cómoda conformidad con esquemas comunes de pensar. Quisiera, no obstante, analizar la obra de Coronado fuera de un marco teórico de polarizaciones (es decir, de supuestas oposiciones entre arte y quehaceres femeninos, pasión y represión, libertad y conformidad, etc.). Después de todo, al enfocarse en la complejidad fenomenológica (para decirlo así) del propio ser, la poeta dio voz a varias subjetividades entrelazadas y discursivamente presentes a la vez: la del ser inquietado por el flujo del tiempo y el poder de la memoria; la del artista capaz de trazar una senda hacia la trascendencia; la del alma que defiende la inocencia e interroga la falibilidad del mundo; la de la persona comprometida por el trabajo al que se le obliga aun cuando se aburra dentro de su situación inmediata. En el grupo de textos aquí bajo discusión -y me limitaré (por cuestiones de espacio) a tres poemas y un ensayo: «Memorias de la Infancia» (1844), «El mundo desgraciado» (1845), «Los Recuerdos» (1845), y «Los genios gemelos: Safo y Teresa» (1848)-, el sujeto poético apunta hacia cuestiones culturales no nítidamente separables en categorías correspondientes a «represión de género», «inquietud romántica» o «identidad femenina», ya que comparten un espacio de composición marcado por preguntas sobre la naturaleza del conocimiento mismo: versan sobre qué conoce y cómo conoce el ser sintiente dentro y a través del tiempo vivido. Analizaré tres núcleos semánticos - «amor,» «cantar»y «espíritus»por medio de los cuales la voz poética de Coronado se concentra en el fenómeno (para decirlo así) de la propia presencia, entendida esta última dentro de su más amplia gama semántica (por ejemplo, sentir, presenciar, estar presente, etc.) La labor poética sobre este conjunto semántico era tan parte del fenómeno de la presencia ponderada por Coronado, como lo fueran la presión de los dedos que sostenían la aguja. Efectivamente, entregándose a un espacio de

2. Risa captada agudamente por Coronado en su poema «La poetisa en un pueblo.» 
composición nutrido por la contemplación de la complejidad de su presente vivido, Coronado desarrolló lo que denominaré una praxis fenomenológica.

Con «praxis fenomenológica» me refiero a la indagación, llevada a cabo por el yo poético de Coronado, acerca de la complejidad de la experiencia vivida; y a la voz del sujeto discursivo que reflexiona sobre las implicaciones del fenómeno de ser dentro, y a través, de marcos temporales. A diferencia del sentido de tiempo cronológico, el tiempo experiencial «casi nunca es cuantificable con precisión» (Hoffman, 2009: 84) y es crucial para «la conformación de nuestra historia vivida» (116). La actividad física realizada en el presente es sólo una hebra en el nexo temporal que condiciona las exploraciones efectuadas por Coronado sobre el ser del sujeto, lo que ella/él ha sido y en lo que se está convirtiendo 3 . Dentro del espacio de la composición, Coronado la persona enfocaba varios campos de percepción: por ejemplo, el del presente «objetivo» en el cual cosía o hacía el trabajo de la casa; el de la memoria, la imaginación y el pensamiento (lo que Hursserl denomina «fantasía»); etc. (Husserl, 2005: 75). Aunque sus dedos estuvieran cosiendo, su mente estaba coordinando puntos en el tiempo, recuerdos en la conciencia y versos en la imaginación: efectivamente, Coronado experimentaba una profundidad de percepción que (como señala Merleau-Ponty) «contiene todo un devenir como un solo agarrón de la mano contiene todo un pedazo de espacio.» (cit. por Mazis, 1996: 74). Para poseer conocimiento de ese «devenir» completo, uno debe hacerse consciente de sus propias qualia experienciales, esto es, de «las cualidades y texturas de la experiencia que son inasibles científicamente» (Hoffman, 2009: 84) (tales como, por ejemplo, las sensaciones inmediatas de la propia mano sosteniendo una aguja, del propio cuerpo presionado contra una silla); pero también es necesario que uno indague en la propia «existencia humana vivida [como] síntesis en desarrollo» del «mundo y de la conciencia» (Alcoff, 2000: 48). Así, la praxis fenomenológica de Coronado, discursivamente anclada en el conjunto semántico de «amor,» cantar»y «espíritus», es un ejercicio en el cual el sujeto poético, enmarañado en lo que Merleau-Ponty elaborara (dentro de The Phenomenology of Perception) como «el mundo de la carne», es empoderado para articular la complejidad inherente en cualquier historia personal del «cuerpo fenomenal» [corps phénomenal].

Tal indagación es emancipatoria para el sujeto poético de Coronado, por cuanto la reflexión fenomenológica acerca de la experiencia de ser en

3. En la discusión que sigue, no asigno un solo sexo o género al sujeto poético de Coronado, ya que en los poemas referidos el enfoque del discurso no es ni el problema de la represión de la mujer, ni una experiencia particularmente «femenina». Por eso, utilizo aquí «la poeta» en vez de «la poetisa». 
el tiempo, particularmente en lo que respecta a la memoria (como lo señala Casey), puede ser «una superación de los límites históricos y preceptúales de la situación inmediata», es decir, «[d]el discurso presente y sus interlocutores reales o virtuales» (2000: 121). Oksala asevera que la fenomenología permite reconocer la «'libertad' [inherente] en la creatividad propia de nuestros cuerpos», libertad nacida del «caracter siempre incompleto de la constitución cultural del cuerpo» (esto es, del «cuerpo fenomenal») (2006: 225). Los núcleos semánticos interrelacionados de «amor,» «cantar,» y «espíritus» revelan la conformación de la historia vivida de un sujeto poético en el tiempo experiencial, tiempo cuyos límites no son definibles ni precisos. Al explorar cuestiones surgidas del ser temporalmente situado (e.g., relaciones entre el «entonces» y el «ahora»; conexiones entre memoria y sensación), los poemas que aquí analizo indican cómo el yo trasciende (o por lo menos, evidencia una conciencia no restringida a) la «situación inmediata,» ya que el yo explaya su voz dentro de un marco fenomenológico que le permite al sujeto poético explorar discursivamente una conciencia de la experiencia encarnada en el tiempo. Un yo cuya indagación goza de coherencia y amplitud no limitadas por las prerrogativas del género, ni por las condiciones culturales impuestas por la Zeitgeist del Romanticismo, ni tampoco por las condiciones físicas del espacio de la composición.

Quisiera dejar claro que no estoy proponiendo que el género cumpla un papel insignificante en el pensamiento y la escritura de Coronado, esto sería un absurdo. Tampoco estoy argumentando en contra de la noción de una subjetividad femenina en la poesía de Coronado: ¿cómo negar (después de todo) la función de una tal subjetividad en poemas como "A Lidia» (1845), en el que la poeta denuncia el «mísero error» cometido por los hombres que hacen de la sensibilidad «femenina» un «yugo» pretexto de la «esclavitud»? (1l. 3-4). Más bien estoy afirmando que un grupo de poemas proveen evidencia de una práctica de indagación filosófica, fenomenológica, aún no analizada dentro de la crítica existente enfocada generalmente en, o la subjetividad femenina, o la subjetividad romántica, de una poetisa. «Poetisa,» como señala Prins, es una categoría cultural decimonónica conflictiva (1999: 209) que conlleva contradicciones: por ejemplo la del aparente desajuste entre la autenticidad de la voz poética de una mujer que canta públicamente sus sentimientos, y los contextos legales y sociales que imposibilitan la autoridad a la mujer (209-213). La vocación de poetisa es un performance para el éxito del cual son necesarias muchas cualidades, la capacidad de negociar convenciones genéricas (en los 
sentidos sexual y estético) entre ellas ${ }^{4}$. Desde luego, las cartas que Coronado escribió a Hartzenbusch abundan en referencias a su capacidad para efectuar tales negociaciones como parte integrante de su carrera literaria. Lo que quisiera evitar aquí es el supuesto de que «conciencia encarnada» y «experiencia situada» estén moduladas discursivamente por una sola y/o predominante subjetividad siempre, inevitablemente, arraigada en cuestiones de represión de género, de política, o de ideología abstractas. Las preguntas que se cultivan en los poemas bajo discusión revelan no solo una subjetividad «femenina» que da voz al lamento de la represión, ni, tampoco, solo una subjetividad «romántica» cuyo yo poético anhela la libertad, sino también -más bien- el desarrollo de una praxis filosófica orientada hacia «el corazón de las cosas» propias del ser humano, complejo a la vez carne, idea y mundo 5 .

\section{BASES DE LA PRAXIS POÉTICA FENOMENOLÓGICA: EL TIEMPO, EL PRESENTE Y EL «YO VERDADERO»}

En la carta a Hartzenbusch (anteriormente citada), la descripción que la poeta hace de sí misma como de apariencia «distraída» frente a los otros, puede parecer consonante con la noción de Husserl sobre la competencia entre elementos en el campo perceptual. Según Husserl, el campo (físico) perceptual y el de la fantasía (o imaginativo) fueran incompatibles: «uno nunca puede dirigir su consideración hacia el campo perceptual y el de la fantasía. Tan pronto como enfocamos nuestra atención en objetos preceptúales, el campo de la fantasía desaparece» (2005: 75). Las precisas distinciones de Husserl entre el campo perceptual y el de la fantasía elevan un «objetivo presente» por sobre aquel que se imagina o se re-presenta en la mente (en la fantasía), en parte porque las cosas en la imaginación pueden ser «vagas» y pueden «ir y venir»: existen «interconexiones estables de las objetividades que pertenecen al campo perceptual de la atención» propone Husserl, en oposición a la «confusión sin sentido con la cual las fantasías e incluso los recuerdos promiscuamente ocurren, produciendo así en nosotros una conciencia de mera representación» (2005: 34).

4. Para más sobre «la poetisa» del siglo XIX, ver: Prins (1996 y 1994) y Vincent (2004). Coronado misma distingue entre la «poetisa» y la «literata,» claramente señalando a la primera como artista auténtica (y no como mera practicante de una vocación literaria); ver su «Contestación» (1999: 56).

5. En palabras de Merleau-Ponty, la existencia encarnada de un ser en un cuerpo «es la unica ruta abierta para que llegue [yo] al corazón de las cosas, ya que me hace de mí todo un mundo y abre de tal manera que a las cosas del mundo les convierta en carne» (1968: 7). 
Sin embargo, en su comentario a Hartzenbusch, Coronado no se describe a sí misma como alguien que experimenta «confusión»o «inestabilidad» (en términos de Husserl); lo que los otros podrían percibir como un «aire distraído» no necesariamente significa que la «contemplación» de Coronado involucrara confusión de su propia parte. De hecho, en la carta a Hartzenbusch la poeta extremeña no narra su experiencia como una en que se viera obligada a elegir concentrarse en una fantasía y no sobre un objeto perceptual (como un calcetín); en cambio le cuenta a Hartzenbusch que ella se dedica a la contemplación mientras realiza sus «labores». Al emplear el término «contemplación,» Coronado refiere el lector a una mezcla o simultaneidad que lejos de ser «confusión,» apunta hacia la amplitud.

Merleau-Ponty propone un papel más interactivo y simultáneamente funcional para la «fantasía» dentro de la percepción encarnada en el tiempo ${ }^{6}$. «El espesor del cuerpo» observa Merleau-Ponty, «lejos de rivalizar con el del mundo, es al contrario el único medio que tengo hacia el corazón de las cosas, al hacerme a mí mismo un mundo y a las cosas carne» (1968: 7). La conciencia del «mundo de la carne» puede abrir la comprensión del conocimiento de que los seres que sienten, están conectados a través del tiempo de maneras profundamente complejas y expansivas que trascienden los marcos temporales comunes de la realidad en el presente. Warnock comenta que la capacidad de alcanzar la conciencia de este «espesor» del mundo experiencial requiere que uno «caiga en un estado como de trance en el cual nuestra afinada conciencia del mundo externo y nuestra disposición a distinguir cosas que difieren espacialmente en ese mundo, es arrullada hasta el descanso» (1987: 93-94 ${ }^{7}$. En otras palabras, la conciencia del mundo de la carne reconoce conexiones y semejanzas entre cosas que por lo general se piensa que son diferentes o fácilmente distinguibles unas de otras, tales como «pasado» y «presente», «muerto»y «vivo», «sueño»y realidad», etc. Sin embargo el «estado como de trance» que se asocia a tal conciencia podría manifestarse en el cuerpo de una persona en práctica de la «contemplación»; podría perfectamente parecer distracción a las otras personas, quienes exigen que el pensador mantenga una «conciencia afinada» durante las tareas que requieren enfoque preciso, destreza rápida o atención visual a sus entornos físicos inmediatos.

6. Alcoff y Oksala ven esta conceptualización fenomenológica de la simultaneidad como un argumento en pro de las ventajas, para el análisis feminista, ofrecidas por las teorías de Merleau-Ponty.

7. Warnock refiere, con «espesor» [del cuerpo fenomenal], al concepto empleado por Merleau-Ponty en Lo visible... 
El número de críticos que han incluido «entre» en los títulos de ensayos sobre Coronado podría sugerir un reconocimiento, por parte de la crítica, de las exploraciones fenomenológicas llevadas a cabo por Coronado sobre los misterios del tiempo, el mundo de la carne y el vértice de la experiencia ${ }^{8}$. Después de todo, el concepto de estar-en-medio es importante en el ideario de Coronado. Por ejemplo, «Memoria de la infancia» presenta un yo poético que habla de su posición liminal entre «el llano donde quedó mi niñez» (1l.4-5) y la segunda mitad de su vida (1l. 53-54); el sujeto hablante de «El mundo desgraciado» se posiciona a sí mismo(a) entre el «sueño de [la] infancia venturosa» (1.15) de Emilio y el final de su propia «larga juventud penosa» (1.16), llevando dentro de sí la habilidad de cantar sobre ambas (ll. 13-14) precisamente porque ella/él se encuentra en un punto misterioso e inefable de conjunción entre los dos. La investigación crítica sobre la función del concepto «entre» en la poesía de Coronado será imprescindible para una aproximación a (por ejemplo) la lastimera pregunta «ipor qué no estoy en tu aurora/ o tú no estás en mi abril?» («Memorias de la infancia», 11. 47-48); o al contexto referido del cuerpo del yo poético, concebido como eje de un vértice de sensaciones y recuerdos (por ejemplo, la indagación del sujeto sobre los «espíritus...peregrinos» que se manifiestan en todos los fenómenos terrestres [ «El mundo desgraciado»] y hacen surgir sensaciones en el cuerpo que recuerda). Sin embargo, la tendencia crítica ha sido a postular a Coronado como una pensadora atrapada entre construcciones genéricas de oposición o inconmensurabilidad: convención y rebelión dentro de una armadura cultural de restricciones impuestas sobre las mujeres ${ }^{9}$.

Encuentro sugerente lo que Kirkpatrick señala como la «simultaneidad» operante en el discurso de Coronado: en los poemas sobre flores (observa Kirkpatrick), «la separación y la identidad simultáneas de la voz lírica y el objeto al que se dirige» (1989: 206) manifiestan «una especie de subjetividad compartida entre el yo hablante y el objeto al que se dirige» (1989: 205). Este concepto de «simultaneidad» parece invitar a los lectores a reconocer la inmersión del sujeto poético en el «vértice de la experiencia» fenomenológico. Pero Kirkpatrick emplea esta idea de «simultaneidad» no con referencia a la conciencia (fenomenológicamente informada) de la experiencia, sino con el fin de revelar una «falacia patética,» una "proyección de la subjetividad» Romántica (1989: 205). El concepto de «falacia patética» desde luego, presume que fuera del espacio dentro del cual la subjetividad poética se desarrolla,

8. Ver, por ejemplo: González-Allende (2004) y Rolle-Rissetto (2008).

9. Ver, por ejemplo, Rolle-Rissetto (2008).

Anales, 23, 2011, pp. 233-257 
hay un mundo «real» que el poeta confunde (esto es, la «falacia»), siendo incapaz de distinguir lo que es visto con el ojo de la emoción (es decir, de lo «patético») y lo que es visto claramente con el ojo de la razón. Ahora bien, la noción de Ruskin de «falacia patética» condenó lo que éste percibía como un error inherente en la sensibilidad Romántica: los Románticos, afirmó Ruskin (en el ensayo de 1856 titulado «De la falacia patética»), erróneamente aceptan «lo extraordinario, o las falsas apariencias» que las cosas nos presentan «cuando estamos bajo la influencia de emoción, o la quimera contemplativa». Este punto de vista crítico postula que la subjetividad intensamente cargada de emociones, será siempre el resultado de o error o confusión, no obstante la importancia de su función dentro de la estética Romántica.

Sin embargo, una praxis fenomenológica poética (como aquella desarrollada por Coronado en los textos que aquí se discuten) no califica a la vidente sensible como víctima del error. Más bien, el sujeto de esta praxis poética, como es consciente de las relaciones latentes entre seres resonantes a través del tiempo dentro del mundo de la carne, no se deja arrastrar por ninguna ficción. La latencia no es una «proyección subjetiva,» no es error, sino -y es importante enfatizar este punto- se reconoce como un hecho de la experiencia vivida, un elemento de la realidad tan real como son la capacidad de recordar el pasado o el sentido del toque. Por ejemplo, en un poema como «Los recuerdos», el sujeto de Coronado no está equivocado(a) (en el sentido de cometer una falacia que el lector reconocería como una proyección errada) cuando indaga en su conciencia de lo que está sintiendo y viviendo. En cambio, examina conscientemente el proceso por el cual la imaginación incorpora una reacción física a la percepción de olores y sonidos en el presente. Ella/él describe la experiencia de estar consciente en el momento, y por lo tanto consciente en la memoria, porque las sensaciones del presente contienen dentro de sí mismas las conmociones latentes del pasado:

«Auras, perfumes de junquillo, trino

de aves amigas, rodeadme: siento

el antiguo placer, aquel contento

que en tiempo a mis amores; imagino

de mi joven cantor sonar vecino

el palpitante, apasionado acento

y las yerbas temblar que sacudía

su planta cuando a mí se aparecía» (ll. 1-8)

La voz poética de «Los recuerdos» les pide a las brisas, las esencias y los sonidos del jardín que la rodeen, no porque el sujeto esté proyectando emociones en ellos, sino porque ellos incitan en ella/él una conciencia latente transmitida por la memoria. La voz dice explícitamente que cuando estos elementos la 
rodean, el sujeto siente «el antiguo placer, aquel contento/que en tiempo a mis amores» (1l. 3-4). Los sonidos y aromas le permiten desencadenar recuerdos e imágenes para un resurgimiento de sensaciones corporales y emociones tales como el oído, la vista y el tacto: cuando percibe las esencias y oye los cantos de las aves, es entonces capaz de «imagin[ar]/de mi joven cantor sonar vecino/el palpitante, apasionado acento» (1l. 3-4); cuando el césped se mueve por la brisa, puede entonces recordar la forma en que el césped se agitaba mientras veía los pasos de su amante acercarse a través del jardín (1l. 7-8). Como el sujeto poético señala, sólo cuando ella/él alcanza a ver un «blanco, débil lirio», se da cuenta de que esta vista le está haciendo experimentar el resurgimiento o despertar del «antiguo amor» latente: «Cuando veo que un blanco, débil lirio,/de los mezquinos que produce el suelo,/mi antiguo amor despierta, impulsa, enciende,/oh! exclamo santo Dios!, quién os comprende?» (1l. 2124). Más adelante, la praxis fenomenológica genera un entendimiento de la naturaleza quiasmática de la experiencia encarnada en el tiempo. Es decir, el sujeto poético ve y también es visto(a); observa a su amante acercarse y es consciente de la concentración de éste, de sus intenciones, a medida que éste avanza.

La praxis fenomenológica de Coronado en «Los recuerdos» evita categorías conceptuales claramente delimitadas (e.g., pasado vs. presente, subjetivo vs. objetivo), pues la poeta describe las conexiones y nexos entre sensaciones y la conciencia dentro y a través del tiempo. Wordsworth definió a la poeta como un autor que «tiene una disposición mayor que la de otros hombres para ser afectado por cosas ausentes como si estuvieran presentes; una habilidad de evocar en sí mismo pasiones que están en realidad lejos de ser similares a las producidas por eventos reales, aún así ... se parecen más a las pasiones producidas por eventos reales que cualquier cosa que, a partir de los movimientos de sus mentes, otros hombres están acostumbrados a sentir dentro de ellos mismos» («Essay, supplementary....»,1802; cit. en Warnock, 1987: 83). Wordsworth, uno de los consumados poetas Románticos de la sensibilidad, sugiere el papel crucial del tiempo y la temporalidad en ese estar-en-el-medio, ese «entre» expresado por el sujeto poético de Coronado: la poeta, capaz de evocar «cosas ausentes como si estuvieran presentes» experimenta el pasado y el instante inmediato como momentos que producen la misma afectación y que son simultáneamente parte de (lo que para la poeta es) lo «real.» Warnock señala que «el tiempo... se compone de una serie de momentos ...que están a la espera, por si el azar nos llevara a una sensación conectada con ellos, o contenida en ellos, que pudiera sacarlos del olvido» (1987: 99). Es esta condición de existencia «entre» (dentro de y entre) sensaciones y momentos, azar 
y recuerdos, que constituye uno de los aspectos más complejos del ser en el tiempo. El estar-entre que los críticos han tendido a atribuir a la subjetividad femenina consciente del conflicto de género, se convierte -dentro del marco fenomenológico de Coronado- en un indicador de emancipación de una situación inmediata de limitaciones físicas y preceptúales asociadas al género. «Al momento de experimentar dos fragmentos de tiempo juntos, el pasado con el presente», afirma Warnock, la exploración de la conciencia propia -o, como lo expresa Coronado, el acto de «contemplación»- puede acceder al «yo verdadero, es decir, al yo que es continuo a lo largo de la vida» (1987: 100); el yo capaz (como dice Casey) de trascender «los límites históricos y preceptúales de lo inmediato», la situación limitada de silla y aguja.

Coronado describe la continuidad de ese yo en «Memorias de la infancia,» observando «cual me recuerda un sonido/ el ave y el tulipán;/ y la fuente que manaba/ el agua que yo bebía /y el campo donde crecía/ la semilla de mi pan!...» (1l. 33-40). Un sonido escuchado en el presente inmediato es inseparable de los sabores, sonidos, sensaciones y momentos vividos de la infancia, los cuales alimentan un proceso continuo de experimentar y de ser. Es más, la conciencia del estado de estar-entre, la conciencia de ser «entre» pasado y presente, estimulación presente y sensación recordada, le otorga al sujeto poético una oportunidad de liberarse a sí mismo(a) de la infelicidad de los límites preceptuales de lo inmediato (lo que Coronado, en este poema, denomina «realidad»): «venid al valle triste en que imagino /sonar de mi cantor el tierno acento,» ruega la poeta a los pájaros, las flores y las brisas; "placeres, dadme, en la ilusión hermosa/ ya que en la realidad no soy dichosa!» (1l, 69-72). (El contraste entre pasado y presente es un tópico romántico por excelencia; sin embargo, vale la pena observar de paso aquí que la Coronado joven poeta romántico se diferencia claramente del Wordsworth maduro poeta romántico, ya que éste creó un sujeto poético agudamente preocupado por un sentido de pérdida, sea de poder, de inocencia, de capacidad espiritual $)^{10}$. Nótese que el yo de «Memorias de la infancia» no habla de realidad y de ilusión como si fueran inconmensurables o antitéticos: por el contrario, la voz poética es consciente de la simultaneidad en la experiencia encarnada, de manera que los estímulos sensoriales presentes están en diálogo con aquellos que se encuentran en la memoria del sujeto, y el sujeto encarnado, el sujeto que siente en el presente inmediato, se convierte en un sitio donde el placer y la infelicidad, la ilusión y la realidad, se consideran

10. Le agradezco esta observación a mi colega Dorothy Noyes. 
naturales, tanto en el presente como en la memoria, dentro de una conciencia del yo de raigambre fenomenológica.

\section{EL MUNDO DE LA CARNE, EL TIEMPO Y «AMOR/AMORES»}

Según Castilla, «para la Coronado... todo el amor en la mujer» fuera «el mismo,» $\mathrm{y}$ «lo que varia[r]a eran las distintas maneras de manifestar ese amor» (1987: 56). Yo no asumo aquí una equivalencia fácil entre «amor»y «feminidad» en el discurso de la poeta extremeña, ya que no todos los casos en que Coronado emplea «amor» registran necesariamente significados de género, ni indican invariablemente que un sujeto particularmente femenino entra al discurso en torno a «amor». Por el contrario, en varios poemas hay un firme marco fenomenológico dentro del cual «amor» metonimiza la experiencia sensible del ser consciente del flujo de tiempo. Coronado desarrolló su propio vocabulario particular para describir y representar la experiencia sensible de latencia dentro del mundo de la carne, y a través del tiempo. El concepto de «amor» empleado por Coronado es muy consecuente con una praxis fenomenológica que postula al cuerpo viviente en y a través del tiempo como la base de la experiencia subjetiva.

El cuerpo permite la acción en el mundo (moverse en el espacio, agarrar objetos, realizar gestos faciales, etc.), y como lo señala Mazis, es la fuente del punto de vista, el cual puede cambiar dependiendo de la conciencia que uno tenga y la reflexión que haga sobre las experiencias encarnadas y sus relaciones en el tiempo y el espacio. De acuerdo con la fenomenología de MerleauPonty, una característica de la percepción es la conciencia de la naturaleza quiasmática de la experiencia encarnada: para Merleau-Ponty, el quiasma se refería a la «doble» naturaleza de la capacidad de un sujeto para percibir y ser percibido $^{11}$. La tradición epistemológica Cartesiana consideraba irremediable la división entre el sujeto de la percepción y el objeto percibido; entre mente y materia; yo y otro. Mientras Husserl problematizó el paradigma dualista mente-cuerpo a través de su intento de entender el funcionamiento de la percepción subjetiva, aun así aceptó la noción de que idealmente, la mente superior puede razonar una vez superadas las restricciones de la encarnación. Ahora bien, Merleau-Ponty abordó sujeto y objeto, mente y cuerpo no como entidades divorciadas o separadas, sino como entidades que se manifiestan en co-existencia, de modo que cosas y fenómenos están conectados más allá de los registros de la visibilidad o el tacto, en una latencia entre cosas. «Dónde

11. Esta doblez, referida por el concepto del «quiasmo,» se explora extensivamente en Lo visible.... (1968). 
estamos para poner el límite entre el cuerpo y el mundo, si el mundo es carne?» pregunta Merleau-Ponty, quien elabora el concepto de «carne» como «no materia, no mente, no sustancia,» sino «medio camino entre el individuo espacio-temporal y la idea, una suerte de principal encarnado que trae un modelo del ser a donde quiera que haya un fragmento del ser» (1968: 2).

A diferencia del empirismo, el cual se apoya en la separación cartesiana sujeto-objeto como la base para la experimentación «racional» en y del mundo, la fenomenología de Merleau-Ponty propone «el vínculo entre la carne y la idea, entre lo visible y la estructura interior que ésta manifiesta y disimula,» y toma como punto de partida que las ideas «no pueden desprenderse de las apariencias sensibles» (Merleau-Ponty, 1968: 1-2). Esta es una conceptualización sustancialmente diferente de la noción Ruskiniana de «falacia patética», que postula una conciencia engañada por sus propias sensibilidades emocionales. Merleau-Ponty, sin embargo, propone que la naturaleza quiasmática del ser carnal facilita el entendimiento gracias a concordancias en nosotros y a nuestro alrededor; el quiasmo abarca al mismo tiempo lo que es y lo que imaginamos que es, lo que vemos y lo que no vemos, sin duda alguna de error o identidad equivocada. Sólo existe la latencia; y una conciencia de las relaciones «latentes» entre el yo y el resto de los seres en y a través del tiempo -es decir, del mundo de la carne- es un dominio ilimitado, por cuanto a la vez «poseemos, y somos poseídos por.....pasado y presente», ser propio y ser ajeno, etc. (268). La conciencia de este ilimitado horizonte del ser informa preguntas tales como la que se formula en el poema «Los recuerdos» de Coronado: «¿Qué ven, qué escuchan, pobre Carolina,/ en la luz y el silencio ojos y oído?» (11. 25-26).

Olkowski destaca que «es la carne la que da a los seres humanos una atmósfera general de comunicación intersubjetiva previa a la cognición y por lo tanto previa a la estratificación social o de género» (7). De hecho, «amor» es uno de los términos más adumbrados de los usados por la poeta en relación con la complejidad temporal de la experiencia sensible del ser encarnado. Por ejemplo, en «Memorias de la infancia», Coronado describe el intento de recordar el «tiempo fugitivo» de la infancia, señalando que no puede verlo «con el rostro»-es decir, como si estuviera mirando o tratando de percibirlo mediante la dirección de su rostro y la atención de su mirada- pero puede recordar claramente sus «amores»: «Yo no sé lo que sonaba.../mas recuerdo mis amores» (11. 17-18). La poeta recuerda su «constante amorío» de criaturas y seres en el mundo natural: «un hermoso tulipán» (1. 20); «la golondrina» (27); etc. Y más, «¡todo me enamoraba/en aquel tiempo querido!» (11. 3334). Así que Coronado emplea «amor» para abarcar la experiencia vivida, 
multisensorial, multitemporal. Warnock observa que «el sentido de identidad personal que cada uno de nosotros tiene es un sentido de continuidad a través del tiempo» (1987: 75). «Amor,» elemento integral de la identidad personal, es inseparable del flujo del tiempo y de las sensaciones guardadas por el recuerdo. El sujeto poético reconoce que las experiencias de la niñez, durantes las cuales «todo me enamoraba», son intensas, cargadas emocionalmente, y forman la conciencia propia como un ser coherente (un ser que vive una «continuidad») mucho después de que la juventud acaba.

Aquí el término «latencia del ser» describe bien el registro semántico dentro del cual «amor» pone en juego sus significados en «Memorias de la infancia», pues la voz poética, que intenta entender ese mundo de la experiencia del pasado lejano en el cual «todo me enamoraba», nota que un solo sonido, oído durante su experiencia vivida presente, puede traerle, a través del recuerdo, el mundo más amplio en que vivía y dentro del cual sus «amores» tomaron forma: «cual me recuerda un sonido/el ave y el tulipán;/ y la fuente que manaba/el agua que yo bebía/y el campo donde crecía/la semilla de mi pan!....» (11. 33-40). La latencia del ser que es una condición para todo lo que se manifiesta en el «vértice de la experiencia», hace posible que un sonido evoque experiencias sensoriales pasadas de cosas vistas, oídas, saboreadas y sentidas. La voz le pide a su hermano (quien recibe sus apostróficas reflexiones) que la incluya «entre sus tiernos amores» cuando más adelante en su vida piense en su niñez (1l. 61-62), aunque el sujeto no esté viva/o físicamente. El sujeto poético espera que Emilio pueda un día poseer la misma conciencia de la latencia del ser, pues sus «tiernos amores» abarcarán esa experiencia más amplia de la infancia, durante la cual uno desarrolla la sensibilidad y la conciencia de ser que trascienden las limitaciones físicas de espacio y tiempo.

\section{LATENCIA DEL SER Y EN EL SER: «CANTO/CANTAR»}

En «El mundo desgraciado,» el sujeto de Coronado posee -guarda dentro«un cantar muy doloroso» o sea «vago, amoroso, indefinible» (ll. Xx). El «cantar» de la poeta es parte de una «historia triste» individual («hay escrito un cantar muy doloroso/en una historia triste que poseo» ll.xx), pero es «indefinible» y «vago» porque es «amoroso;» es decir, imposible de abstraer de la sensación y la experiencia vivida. De hecho, en «El mundo desgraciado», el «cantar» del sujeto poético «encierra»-o posee- la naturaleza quiasmática de la experiencia en el tiempo: la canción comprende la experiencia del yo, la experiencia del hermano y el entrecruzamiento temporal del ser situado de ambos hermanos: 
«memorias para ti de tierno encanto

encierra ese cantar, que lleva unido

al sueño de tu infancia venturosa

el de mi larga juventud penosa» (1l. 13-16)

El «cantar» metonimiza la conciencia que tiene el yo de ser encarnado en el mundo a través del tiempo: contiene, o guarda dentro de sí, recuerdos, imaginación, dolor y placer, y las simultaneidades complicadas de nuestro conocimiento experiencial y el de los otros. «Memorias.../encierra ese cantar,» que no son propiedad de un solo individuo, sino persisten, perduran, laten a través de épocas, vidas, generaciones. Hay una latencia en el canto y la poesía, en el «canto» que la poeta guarda dentro, o canaliza a través, de su voz. Por eso, el sujeto poético concibe este «cantar» como la «unión» de temporalidades (infancia, juventud), condiciones («venturosa», «penosa») y experiencias (la del sujeto poético, la del hermano).

«¿Qué hay en la flor, qué hay en la sombra, el ruido/que penetra tu ser y te fascina?» (1l. 27-28) se pregunta el sujeto: ¿cómo es que una flor o una sombra o un sonido pueden "penetra[r]» el ser del sujeto y llegar a ser parte de su experiencia? «Sobre la copa de la misma encina/el sol que tantas veces ha lucido,/la brisa de la antigua primavera,/ipor qué te agitan cual por vez primera?» (11. 25-32) se pregunta en la misma vena: ¿qué, en la visión de la misma copa de árbol iluminada por la misma luz del sol que uno ha visto repetidamente a lo largo de los años, tiene la capacidad de estimular sensaciones cuya intensidad excede el simple momento de reconocimiento, y surge a través del recuerdo? La praxis poética fenomenológica de Coronado le revela al sujeto que la latencia del ser se encuentra manifiesta más allá de un marco epistemológico basado en una temporalidad delimitada, ya que pasado y presente no están nítidamente divididos, ni (desde el punto de vista experiencial) es un «entonces» fácilmente desentrañable de un «ahora». La latencia del ser más bien se intuye dentro de lo que Warnock llama la «memoria pura»: «en la intuición de la memoria pura, nos conocemos a nosotros mismos. Nos familiarizamos con el espíritu» (1987: 30). El espíritu no se puede ni cuantificar ni medir; lo que pertenece a la esfera «espiritual» se siente, se intuye, incluso se puede saber, pero fuera de los límites de la clasificación. La latencia del ser existe entre, a través de, temporalidades y recuerdos. Por eso, el «cantar» de la poeta vehiculiza el reconocimiento de la latencia del ser, ya que la poesía va más allá del uso cotidiano y común de las palabras en el tiempo, como observa Warnock: «las palabras mismas son objetos físicos, vistos u oídos, y se refieren a clasificaciones.... Las palabras traen de inmediato nuestra duración al contexto del mundo físico que se encuentra orientado de manera práctica» 
(1987: 30-31). Cuando el sujeto se pregunta «¿Qué ven, qué escuchan, pobre Carolina,/en la luz y el silencio ojos y oído?» (ll. 25-26) dirige su pregunta a esta condición de ser «entre», o de explayarse dentro de una continuidad, de manera que ella/él, al mismo tiempo, ve con sus ojos y oye con sus oídos en un momento presente, mientras que la «luz» y el «silencio»-que permiten la sensación en el momento- se extienden más allá de la inmediatez física o epistemológica, y resultan temporalmente indefinibles.

El cantar «vago, amoroso, indefinible» referido por el sujeto de «El mundo desgraciado» trasciende marcos compartimentalizadores, sean el del tiempo dividido en épocas y siglos; el del entendimiento entrenado por la lógica y la objetividad; o el de las leyes, hechas a la medida para reforzar los derechos gozados por los hombres. Por eso, cualquier cosa hecha por «hombres» (en el sentido del ser genérico masculino) -y es de notar que la poeta apunta hacia «sabios dignísimos»-, es muy diferente de lo que la poeta entiende aquí, porque ella habla de cosas que cambian: son «peregrinos,» que se manifiestan en el tiempo y a través del tiempo; "penetran seres» y hacen que la gente se imagine a sí misma y a otros como estando en dos lugares al mismo tiempo, o siendo al mismo tiempo sujetos de placer y dolor, ausencia y presencia, sorpresa y reconocimiento.

«Yo nada sé; filósofos profundos que los misterios de la vida entienden, sabrán de aquellos que el espacio hienden en recuerdos espíritus fecundos; yo las leyes ignoro de esos mundos que los sabios dignísimos comprenden; pero sé que en la tierra, peregrinos, hay espíritus mil que son divinos.» (1l. 33-40)

A diferencia de los filósofos y los sabios, el sujeto poético niega acordarse a sí mismo/a un conocimiento de «esos mundos» abarcados por las muchas «-logías» compartimentalizadoras de la sabiduría: «Yo nada sé.../.../de los misterios de la vida» definidos por los «sabios dignísimos». El yo de «El mundo desgraciado» sabe de "espíritus mil peregrinos», que se manifiestan a través de sensaciones cuyo cargo de latencia no se puede ni medir ni pesar de acuerdo con los marcos espacio-temporales comunes. Por eso, son «divinos»: «Pero sé que en la tierra, peregrinos,/hay espíritus mil que son divinos». Dios trabaja a través del ser humano, hace a los humanos vibrar y sentir por medio de divinos «espíritus peregrinos» que pasan por la brisa, las fragancias, la vista, y cuya latencia de ser incita respuesta -despierta «memorias olvidadas»- en el pensador divinamente inflamado. Las «memorias olvidadas» son traídas a la vida a través de olores, visiones: están latentes tanto en uno mismo como en 
el mundo, y las conexiones siempre están ahí, con anterioridad, precediendo la habilidad que uno tiene para reconocerlas:

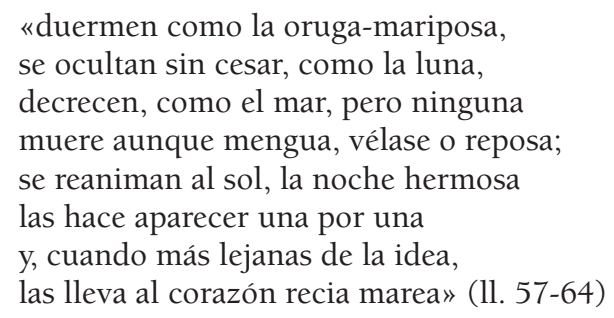

Cuando pareciera que la mente tuviera el control, que pudiera organizar al mundo por medio de leyes, decretos, estudios, sabiduría..., precisamente en este momento ilusorio de «la idea», los recuerdos y las experiencias latentes se manifiestan a través de sensaciones que revelan la temporalidad multi-modal de la percepción y el afecto: «y, cuando más lejanas de la idea,/las lleva al corazón recia marea» (1l. 57-64). Por eso, la «marea» que el «corazón» experimenta no está divorciada de la «idea»; en este pasaje del poema, «lejana» no lleva tal carga semántica. Por el contrario, Coronado observa que la «marea» de la experiencia encarnada y la «idea» de lo que percibe en el momento vivido comparten la latencia, están conectadas de formas que ya se encuentran dentro de memoria, ser, sensación.

Warnock apunta hacia la importancia de la sintaxis para cualquier representación discursiva de la relación entre recuerdo y experiencia inmediata: «La sintaxis misma que las une depende del concepto práctico de tiempo» (1987: 30-31). El sujeto poético, agudamente consciente de la necesidad de emplear la sintaxis para dar énfasis a su propia conciencia del tiempo, posiciona la palabra «cuando» como eje central del fenómeno experiencial que va describiendo: las «memorias olvidadas» laten en el medio ambiente y en las cosas (esto es, en la oruga-mariposa, la luna, las estrellas), pero cuando -palabra que posiciona al yo en un momento donde se unen sensaciones y memorias, pasado y presente, en una temporalidad compleja y amplia- todas las memorias latentes parezcan «más lejanas de la idea,/las lleva al corazón recia marea» (1l. 63-64). Huyssen observa que el «estatus temporal de cualquier acto de memoria es siempre el presente y no, como quisiera cierta epistemología naif, el pasado mismo» (Cit. Por Bal, 1999: 181). Coronado elabora precisamente esta conciencia de la temporalidad presente de la memoria; la praxis fenomenológica llevada a cabo por medio de la poesía le permite a la poeta trazar «la tenue fisura entre pasado y presente» que constituye la memoria» (Huyssen, cit. por Bal, 1999: 181). Experiencia y memoria ambas están en el mundo, y el mundo en ellas, de modos que una práctica de la 
conciencia fenomenológica y un discurso poético sintácticamente sofisticado pueden traer a la luz.

En su ensayo en que compara a Safo y a Santa Teresa, Coronado describe cómo las dos escritoras comparten una sensibilidad de latencia del ser a través del tiempo y el espacio: «Tengo para mí que, nacidas en apartados climas y sin haberse visto nunca, habían de presentirse y agitarse, y se habían de entender y amar por el misterioso impulso de sus almas» (19). Esta latencia obedece a las leyes físicas de correspondencia y simpatía similares a aquellas del magnetismo o la gravedad: «Esos fenómenos que en el orden físico se observan, esa convulsión del mar por el movimiento de la luna, se repiten en el orden moral con las mismas incomprensibles relaciones. El ave que adivina la tormenta, la brújula que marca el polo, no son mas sensibles que el corazón humano en las fibras de su amor» (19).

Coronado parece sugerir que «las mujeres» son susceptibles de experimentar tales «convulsiones,» y así, las experiencias de Safo y de Teresa pueden parecer femeninas: iquién aparte de una mujer (pregunta Coronado retóricamente, escribiendo sobre Teresa) sería capaz de entender «cómo la sangre hierve en nuestras venas en esas horas de fiebre en que nos abrasa la pasión», «cómo el recuerdo de una mirada nos hace vibrar nuestras fibras» $\mathrm{o}$ «esa gran batalla del espíritu contra el corazón»? (28). Sin embargo, como señala Coronado más adelante en el mismo ensayo, oposiciones simplistas, tales como «la división del amor profano y del amor divino»o «esa gran batalla del espíritu contra el corazón», son «falsas» (38), porque las cosas sólo parecen «profanas» o «divinas», «espirituales» o «asuntos del corazón» a causa de las variaciones en las circunstancias históricas o de diferencias en las percepciones, que están culturalmente condicionadas. Es importante notar aquí que Coronado rechaza de manera rotunda una postura crítica polarizadora u oposicional para organizar sus observaciones sobre Safo y Teresa: al contrario, intenta matizar la latencia de las cosas que unen a dos escritoras tan aparentemente separadas por siglos y geografía. De hecho, Safo y Teresa, aunque separadas por milenios, aunque divididas por la geografía y la fe, son «un engendro de la madre eternidad, para quien los siglos son minutos»: la «naturaleza» dio a luz a Safo y a Teresa "casi a un mismo tiempo», de manera que en las voces y la experiencia de las dos mujeres están latentes «un mismo soplo de vida, y la misma inspiración inmortal» (38). Tanto Safo como Teresa son cantores no sólo porque produjeron poesía, sino porque sus voces hicieron manifiesto aquello que está latente a través de la eternidad y el tiempo. Las sensibilidades de Safo y de Teresa pudieran parecer particularmente «femeninas» a los lectores de mediados del siglo XIX- cuya imagen de la poetisa se nutría de 
la pathos y del drama legendarios del suicidio de Safo, pretexto de muchos versos escritos por mujeres (incluso por Coronado misma) durante la época ${ }^{12}$ : el salto de Safo por Leucades parecía captar la esencia «amorosa» femenina, orientada hacia un sacrificio natural en la mujer ${ }^{13}$. Pero el cantar de Teresa y Safo, según Coronado, es capaz de condensar la eternidad en el presente y de trascender las divisiones entre masculino y femenino, carnal y espiritual, represión y libertad, a través de una «inspiración inmortal».

Por eso, «cantar», concepto tan importante para el vocabulario de indagación fenomenológica empleado por Coronado, conlleva connotaciones semánticas que se remontan a la antigüedad del lamento, especie de vocear ritual asociado con ritos de pasaje (el matrimonio, la muerte, etc.). El lamento era elemento integral en los ritos que marcaban el flujo de tiempo «dentro de la historia de una familia», fundamental para «la auto-conciencia y la memoria propia del oikos» (Stears, 2008: 149). El cantor de un lamento no solo se comprometía a "prácticas rituales que cumplían funciones comunitarias» (Klinck, 2002: 28) dentro del oikos, sino también se entregaba al sensualismo de la emotividad propia del momento vivido (28). Cuando Coronado emplea el concepto del cantar para referirse a la «inspiración inmortal» compartida por Safo y Teresa, la «inmortalidad» de esa «inspiración» comparte con los lamentos antiguos una capacidad de condensar la historia y la presente de un ser y su oikos -esto es, un ser situado-y de hacer patente «en un mismo soplo de vida» la latencia de la experiencia del ser situado a través del tiempo y del espacio.

\section{ESPÍRITUS E INTERMUNDUM: LO AUSENTE, PRESENTE}

En este sentido, la exploración de latencia, de las continuidades temporales y de la complejidad experiencial le permite a su sujeto poético trascender la «vacilación continua» entre opuestos irreconciliables que, como Gies ha señalado, es supuestamente típico del discurso Romántico español. Según Gies, la subjetividad «romántica» se encuentra fuera de equilibrio a causa de la lucha entre «vida/muerte, amor/odio, luz/oscuridad, ángel/diablo», la cual informa la «desesperación ontológica» que caracteriza a buena parte de la literatura de mediados del siglo XIX (1989: 147). Sin embargo, el cantar (como lo concibe Coronado) re-orienta las cosas que sólo pueden parecer opuestas

12. Ver el ciclo de versos sobre Safo escrito por Coronado, en particular «El salto de Leucades».

13. Para mas sobre la imagen de Safo en la cultura de mediados del XIX, ver: Barrero Pérez; Lipking; Prins; y Vincent. 
o desconectadas: la «inspiración inmortal» permite que el canto, o «cantar,» dé voz a la experiencia carnal compartida por, y a través de, el mundo, y que articule una conciencia transformativa de la temporalidad multimodal del ser experiencial.

En el vocabulario poético de indagación fenomenológica de Coronado, «canto» $\mathrm{y}$ «cantar,» «amor» $\mathrm{y}$ «amores» se refieren a la conciencia del sujeto de una experiencia que comprende tanto lo que está «aquí/allí» (la situación inmediata; lo que uno ve alrededor o frente a uno en el momento presente; lo que uno siente), y lo que «no está aquí/no está allí» (lo que está en el pasado o en la distancia; lo que es imaginado o recordado; lo que sólo parece ser; lo que uno puede sentir más allá de lo que puede ver). De hecho, Coronado comparte una conceptualización más Wordsworthiana de poesía como evocación del poder latente en las cosas; como lo expresa Wordsworth en el «Ensayo suplementario» al prefacio de sus poemas en 1815 , la primera tarea del poeta es «evocar y comunicar el poder» (31). La praxis fenomenológica poética de Coronado busca entender las relaciones entre cosas que, lejos de ser opuestas e irreconciliables, son parte integral de la conciencia en y de la temporalidad. Así lo hace en un espacio composicional que está «entre» o en medio de estados de ser en el tiempo. El concepto de Coleridge de «intermundum» es útil aquí, como espacio dentro del cual el genio poético «renegocia relaciones» entre «pensamiento y realidad» (Burwick, 1996: 37). Este intermundum es un «lugar óntico» que estaría fundado en la mente misma, en la memoria, el deseo, el miedo o en la conciencia de la presencia divina, como lo expresara el crítico romántico Thomas McFarland en 1819 (cit. por Burwick, 1996: 41). Es un espacio quiasmático en el cual los fenómenos del ser surgen y se cruzan; en el cual el sujeto poético percibe lo que «la mente da tanto como recibe» ${ }^{14}$.

Nótese que no me refiero a un «modo privilegiado de conciencia que supera el dualismo cartesiano» de carácter romántico, o a un «Orfismo romántico» (Clark, 1997: 29): no leo al sujeto poético de Coronado como «poseedor de un poder único que podría tener la llave hasta del inframundo» (Clark, 1997: 29). La poeta evita discursar dentro de una subjetividad poseedora de una superior conciencia; no comete lo que Ruskin identificara como el error de la «falacia patética», nacido del sentido romántico de entusiasmo poético como generador de percepciones privilegiadas sobre el orden y significado de la naturaleza ( $\mathrm{La}$ «falacia» siendo, por supuesto, que los estados afectivos fugaces del individuo podrían abarcar hasta los misterios perennes del universo.) Sin embargo, la poeta sí comparte con poetas románticos como

14. Burwick (41), citando al texto de McFarland.

Anales, 23, 2011, pp. 233-257 
Wordsworth una profunda conciencia del flujo del tiempo, y de lo complicado -de lo difícil- que sería distinguir entre pasado y presente, memoria y sensación, dada la latencia compartida por todas las cosas que vivieron, viven, y vivirán. Lejos de servir como pretexto para la exaltación del/de la poeta, el yo poético en posesión de esta conciencia viene a ser metonímico del fenómeno de la continua transformación compartida entre todas las cosas que se encuentran en flujo del tiempo.

Tal poder transformativo tiene su fuente en la «agencia fantasmática» (Clark, 1997: 26). La agencia fantasmática es «ilocalizable», por cuanto el espacio de composición «deforma las distinciones de interior y exterior, concepción y recepción. Es un lugar de agencias no limitables a una sola situación... que deforman los límites aparentes entre yo y otro, acto y pasividad, parálisis y don» (27). Coronado refiere a lo «ilocalizable» de la experiencia dentro del tiempo, a la hora de reconocer, en el poema «El mundo desgraciado», a los «espíritus mil que son divinos» que «hienden el espacio» y, «peregrinos», hacen manifiesta la latencia de todas las cosas «en recuerdos». «Espíritus» viene a ser un núcleo semántico clave para la poeta, ya que le sirve para captar la latencia -esto es, la continuidad ilocalizable- de todas las cosas.

He propuesto que los núcleos semánticos entrelazados de «amor,» «cantar» $\mathrm{y}$ «espíritus» le permiten a Coronado discursar sobre este ser-fenómeno de múltiples dimensiones. El yo poético desarrollado por Coronado explaya una performatividad discursiva, su «cantar» el heredero del lamento antiguo cuyo papel participatorio (dentro del esquema cultural de los ritos de pasaje) era no sólo conmemorativo, sino también abiertamente experiencial. No obstante, la continuidad del cantar/lamento -sea ritual, sea ordinaria la situación inmediata de su performance- es su capacidad para dar voz a una conciencia (personal, comunal) del entrelazamiento de las cosas que han existido y que siguen existiendo. Coronado conceptualiza «el cantar» como un medio léxico de denotar los «espíritus peregrinos» cuya latencia en y a través del tiempo sea difícilmente representable. Las múltiples subjetividades comprendidas en estos espíritus, que resisten mapearse, que informan lo que «es difícil» (como comentara Coronado a Hartzenbusch), ¿después de todo, no las habrá intentado trazar el yo poético de Coronado, a la hora de nombrarlas por medio de las voces «amor», «cantar» y «espíritus»? Y la contemplación a la que se entregaba Coronado, ¿no le habrá permitido a la poeta componer unos versos capaces de rastrear el fenómeno de su propia multi-dimensionalidad, esto es, de dar voz a la mujer sentada, a la persona, al cantor, al poeta, al complejo humano que Coronado misma estuviera consciente de ser? Sean de índole retórico las preguntas que acabo de hacer, no lo es la última que hago al terminar 
la presente discusión: al describir a la esencia quiasmática e indefinible de la experiencia como «una explosión estabilizada» (Lo visible: 268), ¿nos ofrecerá Merleau-Ponty una puente hacia el discurso poético de Coronado, a la vez distinta a, y reconciliadora entre, los marcos críticos polarizantes de «liberación romántica» (y todo lo que ésta pueda conllevar referente a pasión, ruptura de límites y «explosión» cultural) y de encerramiento doméstico (espacio ideológico dentro del cual cose y borda, eternamente, un ángel del hogar encarnizador de la estabilidad misma)?

\section{BIBLIOGRAFÍA}

AlCOFF, Linda Martin, «Phenomenology, Post-structuralism, and Feminist Theory on The Concept of Experience,» en Linda Fisher y Lester Embree, eds., Feminist Phenomenology, Dordrecht/Boston/London, Kluwer Academic Publishers, 2000, pp. 39-56.

BAL, Mieke, «Memories in the Museum: Preposterious Histories for Today,» en Mieke Bal, Jonathan Crewe, et al., eds., Acts of MemorY: Cultural Recall in the Present, Hanover, University Press of New England, 1999, pp. 171-190.

BARRERo PÉREZ, Oscar, «Imágenes de Safo en la literatura española (II). El romanticismo», Cuadernos de Ilustración y Romanticismo, 12 (2004), pp. 61-75.

Boynton, Susan, «Women's Performance of the Lyric», en Anne L. Klinck y Ann Marie Rasmussen, eds., Medieval Women's Song: Cross-Cultural Approaches, University Park, PA, Pennsylvania State University Press, 2002.

BRYson, Valerie, Gender and the Politics of Time: Contemporary Debates, Bristol, Policy Press, 2007.

Burwick, Frederick, Poetic Madness and the Romantic Imagination, University Park, PA, Pennsylvania State University Press, 1996.

CASEY, Edward S., Remembering: A Phenomenological Study, Bloomington/Indianopolis, Indiana University Press, 2000.

Castilla, Alberto, Carolina Coronado de Perry, Madrid, Ediciones Beramar, 1987.

CLARK, Timothy, The Theory of Inspiration: Composition as a crisis of subjectivity in Romantic and Post-Romantic Writing, NY/Manchester, Manchester University Press, 1997.

Coronado, Carolina, «Memorias de la Infancia», Poesías, Noël Valis, ed., Madrid, Castalia, 1991, pp. 165-167.

— «El mundo desgraciado», Poesías, Noël Valis, ed., Madrid, Castalia, 1991, pp. 186-188.

— «Los Recuerdos», Poesías, Noël Valis, ed., Madrid, Castalia, 1991, pp. 237-239.

— «A Lidia», Poesías, Noël Valis, ed., Madrid, Castalia, 1991, pp. 520-522. 
— «La poetisa en un pueblo», Poesías, Noël Valis, ed., Madrid, Poesías, Noël Valis, ed., Madrid, Castalia, 1991, pp. 369-370.

— «El salto de Leucades», Poesías, Noël Valis, ed., Madrid, Poesías, Noël Valis, ed., Madrid, Castalia, 1991,

- «Los genios gemelos: Safo y Santa Teresa», Obra en Prosa, III, Gregorio Torres Nebrera, ed., Mérida, Editora Regional de Extremadura, 1999, pp. 13-52.

- «Contestación a Madame Amelie Richard», Obra en Prosa, III, Gregorio Torres Nebrera, ed., Mérida, Editora Regional de Extremadura, 1999, pp. 56-60.

- «Cartas de Carolina Coronado a Juan Eugenio Hartzenbusch», Obra en Prosa, III, Gregorio Torres Nebrera, ed., Mérida, Editora Regional de Extremadura, 1999, pp. 415-454.

EZAMA GIL, Ángeles, «El canon de escritoras decimonónicas españolas en las historias de la literatura», en Luis F. Díaz Larios, Jordi Gracia, et al., eds., La elaboración del canon en la literatura española del Siglo XIX: II Coloquio de la Sociedad de Literatura Española del siglo XIX, pp. 261-266.

GIES, David T., «Imágenes y la Imaginación románticas», en David T. Gies, ed., Romanticismo, Madrid, Taurus, 1989, pp. 141-151.

GONZÁlEZ-ALLENDE, Iker, «Entre la modestía y el orgullo: Las coordenadas metapoéticas de Carolina Coronado», Decimonónica 1.1 (Fall 2004), pp. 33-51. Hoffmann, Eva, Time, New York, Picador, 2009.

HUSSERL, Edmund, «Phantasy and Image Consciousness» (third principal part of the lectures from the winter semester 1904.1905 on 'principal parts of the phenomenology and theory of knowledge')», en Phantasy, image, unconsciousness and memory (1898-1925), Trad. John B. Brough, Dordrecht, Springer Verlag, 2005, pp. 1-205.

KIRKPATRICK, Susan, Las románticas: Escritoras y subjetividad en España, 18351850, Madrid, Cátedra, 1989.

KLINCK, Anne, «Sappho and her daughters: Some parallels between ancient and medieval women's song», en Anne L. Klinck y Anne Marie Rasmussen, eds., Medieval Women's Song: Cross-Cultural Approaches, University Park, PA, University of Pennsylvania Press, 2002, pp. 15-28.

LIPKING, Lawrence, Abandoned Women and Poetic Tradition, Chicago, University of Chicago Press, 1988.

MAZIS, Glen, «Matter, Dream and the Murmurs among Things», en Veronique M. Foti, ed., Merleau-Ponty: Difference, Materiality, Painting, Highlands, NJ, Humanities Press, 1996, pp. 72-89.

MERLEAU-Ponty, Maurice, The visible and the invisible:Followed by Working Notes, Trad. Alphonso Lingis, Evanston, Northwestern University Press, 1968.

- «Eye and Mind», The Primacy of Perception and other Essays on Phenomenological Psychology, The Philosophy of Art, History and Politics, James M. Edie, ed., Evanston, Northwestern University Press, 1964, pp. 159-190. 
Miller, Christopher R., The Invention of Evening. Perception and Time in Romantic Poetry, Cambridge, Cambridge University Press, 2006.

OKSALA, Johanna, «Female Freedom: Can the Lived Body be Emancipated?» en Dorothea Olkowski y Gail Weiss, eds., Feminist Interpretations of Maurice Merleau-Ponty, University Park, Pennsylvania State University Press, 2006, pp. 209-228.

OlKOWSKI, Dorothea, «Introduction: The Situated Subject», en Dorothea Olkowski y Gail Weiss, eds., Feminist Interpretations of Maurice Merleau-Ponty, University Park, Pennsylvania State University Press, 2006, pp. 1-24.

PARKER, Rozsika, The Subversive Stitch: Embroidery and the Making of the Feminine, London/NY, I.B. Tauris, 2010.

PÉrez GonzÁlez, Isabel María, Carolina Coronado (del romanticismo a la crisis fin de siglo), Badajoz, Los libros del Oeste, 1999.

PrInS, Yopie, Victorian Sappho, Princeton, Princeton University Press, 1999.

- «Sappho's Afterlife in Translation,» en Ellen Greene, ed., Re-Reading Sappho: Reception and Transmission, Berkeley, University of California Press, 1996, pp. 36-67.

ROLLE-RISSETTO, Silvia, «Entre moderación y velada subversión: la imaginería y simbología en el ideario feminista de C. Coronado», Nueva Revista del Pacífico, 53, 2008.

RUSKIN, John, «De la falacia patética» (1856), en Modern Painters (III), The Works of John Ruskin, vol. 5, eds. E.T. Cook y Alexander Wedderburn, London, George Allen, 1903, pp. 201-220.

Simón PALMER, María del Carmen, «Escritoras Españolas del Siglo XIX o el miedo a la marginación,» Anales de Literatura Española, 2 (1983).

STEARS, Karen, «Death Becomes Her: Gender and Athenian Death Ritual», en Ann Suter, Ed., Lament: Studies in the Ancient Mediterranean and Beyond, Oxford, Oxford University Press, 2008, pp. 139-155.

VALIS, Noël, «Introducción», en Carolina Coronado, Poesías, Noël Valis, ed., Madrid, Castalia, 1991, pp. 7-41.

Vincent, Patrick H, The Romantic Poetess: European Culture, Politics and Gender, 1820-1840, Lebanon, University Press of New England, 2004.

WARnOCK, Mary, Memory, London/Boston, Faber and Faber, 1987.

WORDSWORTH, William, «Essay Supplementary to the Preface» (1815), en Prefaces and Prologues to Famous Books, with Introductions and Notes, The Harvard Classics, vol. 39, New York, P.F. Collier \& Son, 1910, pp. 311-336.

Fecha de recepción: 28/04/2010

Fecha de aceptación: 07/05/2010 